\title{
On the identity of Pettalus cimiciformis and $P$. brevicauda (Opiliones, Pettalidae) from Sri Lanka
}

\section{Citation}

Giribet, Gonzalo. 2008. "On the Identity of Pettalus Cimiciformis and P. Brevicauda (Opiliones, Pettalidae) from Sri Lanka." Journal of Arachnology 36 (1) (April): 199-201. doi:10.1636/ h07-70sc.1.

\section{Published Version}

doi:10.1636/h07-70sc.1

\section{Permanent link}

http://nrs.harvard.edu/urn-3:HUL.InstRepos:14400078

\section{Terms of Use}

This article was downloaded from Harvard University's DASH repository, and is made available under the terms and conditions applicable to Other Posted Material, as set forth at http:// nrs.harvard.edu/urn-3:HUL.InstRepos:dash.current.terms-of-use\#LAA

\section{Share Your Story}

The Harvard community has made this article openly available.

Please share how this access benefits you. Submit a story.

\section{Accessibility}




\title{
SHORT COMMUNICATION
}

\section{On the identity of Pettalus cimiciformis and P. brevicauda (Opiliones, Pettalidae) from Sri Lanka}

\author{
Gonzalo Giribet: Department of Organismic and Evolutionary Biology \& Museum of Comparative Zoology, Harvard \\ University, 26 Oxford Street, Cambridge, Massachusetts 02138, USA. E-mail: ggiribet@oeb.harvard.edu
}

\begin{abstract}
Among the most enigmatic Cyphophthalmi are members of the genus Pettalus, a monophyletic group endemic to Sri Lanka. To date three species have been named, Pettalus cimiciformis (O. Pickard-Cambridge 1875), P. brevicauda Pocock 1897, and P. lampetides Sharma \& Giribet 2006. However, the identity of the two XIX Century species remains confusing. Here the identity of the three original Pettalus specimens is revised based on their re-examination and comparison to the original descriptions, which do not match the redescriptions of these species published in the monograph of Hansen \& Sørensen (1904).
\end{abstract}

Keywords: Holotypes, male, arachnid, taxonomy

Among the most enigmatic Cyphophthalmi are the members of the genus Pettalus, a monophyletic group endemic to Sri Lanka (Boyer et al. 2007). To date, three species have been named, Pettalus cimiciformis (O. Pickard-Cambridge 1875) [described as Cyphophthalmus cimiciformis], P. brevicauda Pocock 1897, and P. lampetides Sharma \& Giribet 2006 (Pickard-Cambridge 1875; Pocock 1897; Sharma \& Giribet 2006) with ca. 10 additional species known but still undescribed (Sharma \& Giribet 2006). Both nineteenth century species were redescribed by Hansen \& Sørensen (1904) and specimens are deposited at The Natural History Museum, London (NHM). However, confusion still remains in the literature with respect to the identity of the types of $P$. cimiciformis and $P$. brevicauda. The original descriptions of $P$. cimiciformis and $P$. brevicauda do not match the redescriptions of Hansen \& Sørensen (1904), and a loan of the supposed two holotypes from The Natural History Museum did not immediately resolve this controversy since both were labelled as $P$. brevicauda.

According to the original description by O. Pickard-Cambridge (1875), the single specimen of Pettalus cimiciformis is an adult male (based on the original illustrations) "...received from Mr. G. H. K. Thwaites, by whom it was sent to me from Ceylon." G.H.K. Thwaites was then the director of the Peradeniya Botanical Gardens, and I had originally suggested that $P$. cimiciformis may have originated from there (the type locality was listed as "Ceylon"). These gardens were visited by G. Giribet, S.L. Boyer, I. Kuranarthna, and P. Sharma in June 2004 and 52 specimens of a Pettalus species were obtained during the visit. However, the species from Peradeniya differs considerably from $P$. cimiciformis. These specimens have appeared in recent publications as Pettalus cf. brevicauda (Boyer et al. 2007; Boyer \& Giribet 2007; Pinto-da-Rocha et al. 2007). Pettalus cimiciformis was reported to have dimensions of "length of $1 \frac{3}{4}$ line, breadth nearly 1 line," and a scale bar reported to be shown at real size in his (O. P.-C.) plate XIII, figure $3 \mathrm{f}$ measures almost $4 \mathrm{~mm}$. The second species, described by R.I. Pocock (1897), was based on two specimens from Pundaluoya (spelt Punduloya), in the Central Province, Sri Lanka, collected by E.E. Green. The largest specimen, upon which the description was based, measured $3.8 \mathrm{~mm}$ in length and $2.5 \mathrm{~mm}$ width according to the original description and was said to differ from $P$. cimiciformis "in its relatively weakly lobate 'tail' and much smaller process on the fourth tarsus [the adenostyle]" (Pocock 1897:290). He also stated that "A second smaller specimen, obtained by Mr. Green, has no process on the fourth tarsus, and the last tergite scarcely lobate and not grooved. This specimen is probably either young or of a different sex from the type." The illustration of the prosomal ventral complex seems to indicate a closed gonostome,
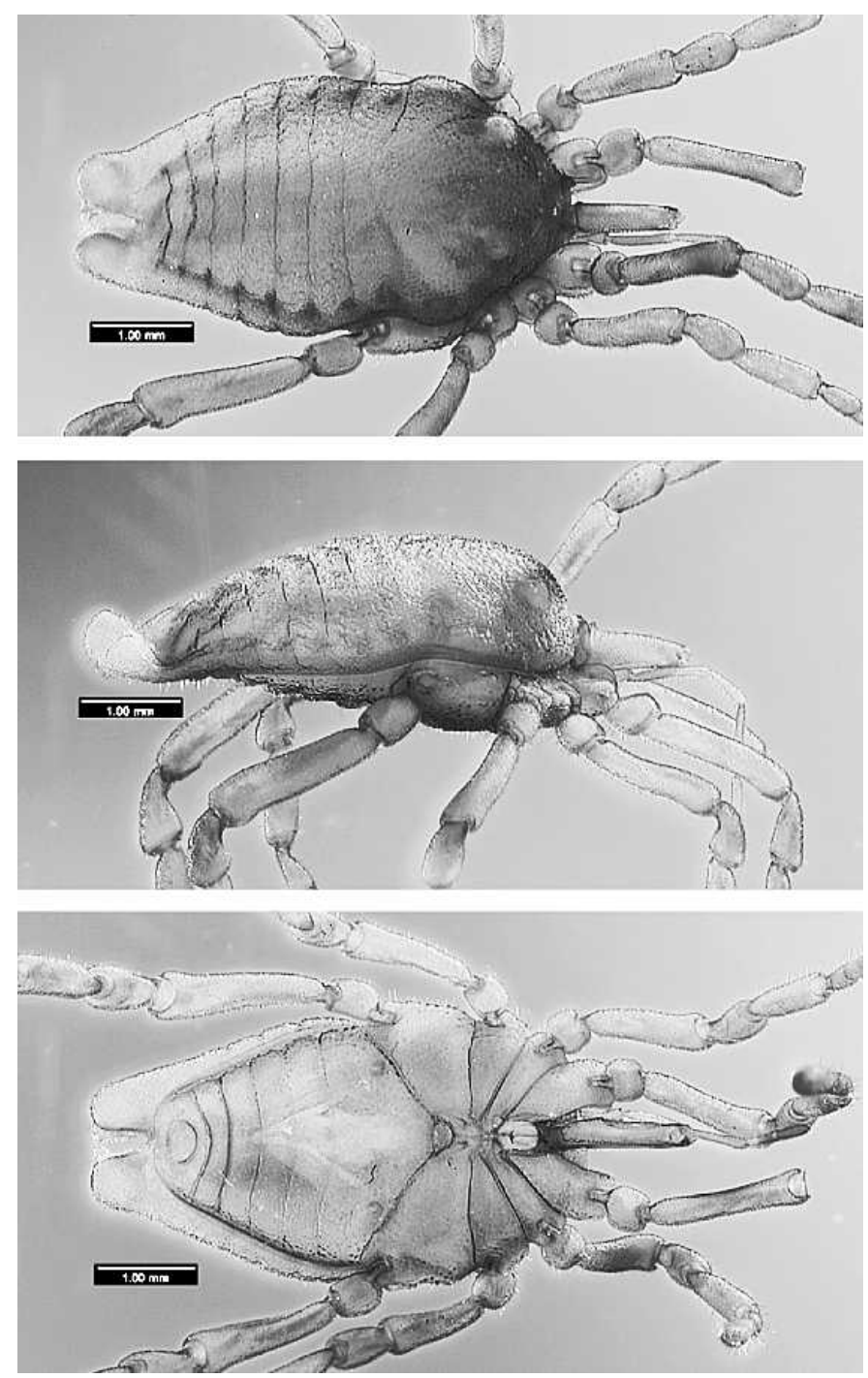

Figure 1.-Holotype of Pettalus cimiciformis in dorsal (top), lateral (center) and ventral (bottom) views. Scale bar $=1 \mathrm{~mm}$. Specimens were photographed under a Leica MZ 12.5 dissecting microscope using a mounted JVC KY-F70B digital camera. Digital images captured at different focal planes were assembled using the application Auto-Montage Pro Version 5.00.0271 by Syncroscopy. 

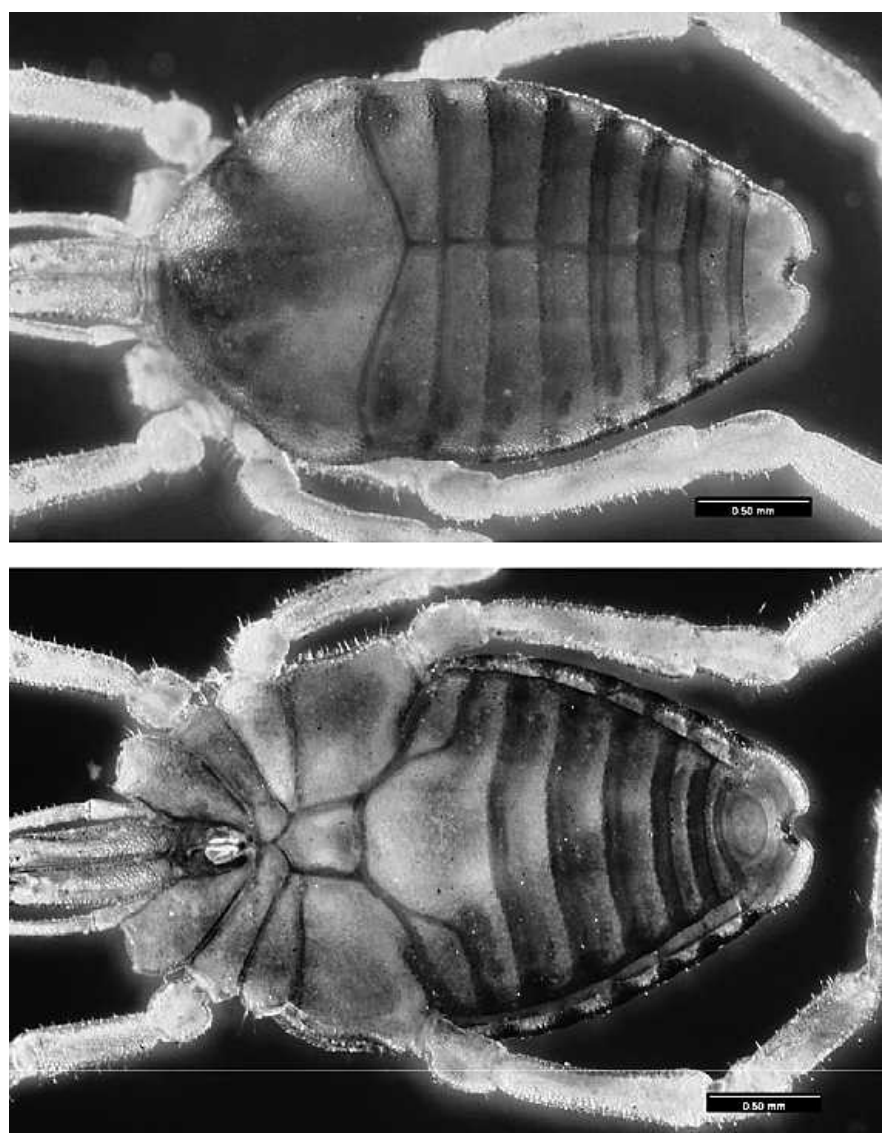

Figure 2.- Holotype of Pettalus brevicauda in dorsal (top), and ventral (bottom) views. Scale bar $=0.5 \mathrm{~mm}$.

typical of immature specimens. Although we visited Pundaluoya in June 2004, we were not able to locate primary forest, and we did not locate specimens of Pettalus in the tea plantations. In 2001 I received a loan from NHM supposedly containing the types of both species. However, both specimens, a large male and a much smaller subadult male, were labelled in pencil and using the same font as "Pettalus brevicauda" from "Punduloya" collected by E.E. Green.

Consultation of Hansen \& Sørensen (1904) did not resolve this issue even though it supposedly provided detailed illustrations of both species. Their Plate III, figure 3a, labelled "P. brevicauda Poc." [italics missing in the original] (see also figure legends on their page 168) and description - the largest specimen reported to measure $4.6 \mathrm{~mm}$; the smallest reported to measure $3 \mathrm{~mm}$ - corresponded to the larger specimen borrowed from NHM. In contrast, P. cimiciformis was reported to measure $3.6 \mathrm{~mm}$, considerably smaller than the other specimen (Hansen \& Sørensen 1904: 103). Furthermore, the illustrations of this species (their Plate III, fig. 2) do not seem to correspond to either specimen described by Pocock (1897; see discussion below).

After a second visit to the collections of the NHM in June 2007, I was able to examine a third Pettalus specimen, also labelled as "Pettalus brevicauda, Poc. (young), Punduloya (Ceylon), E.E. Green coll." and solve the mystery about the identity of the two oldest Pettalus species. In total, the NHM collection included three specimens of Pettalus illustrated in Figs. 1-3. The largest specimen ( $5 \mathrm{~mm}$ measured in dorsal view from anteriormost carapace border to end of the "tail," as is currently the standard for measuring Cyphophthalmi), an adult male, is unmistakably the holotype of $P$.
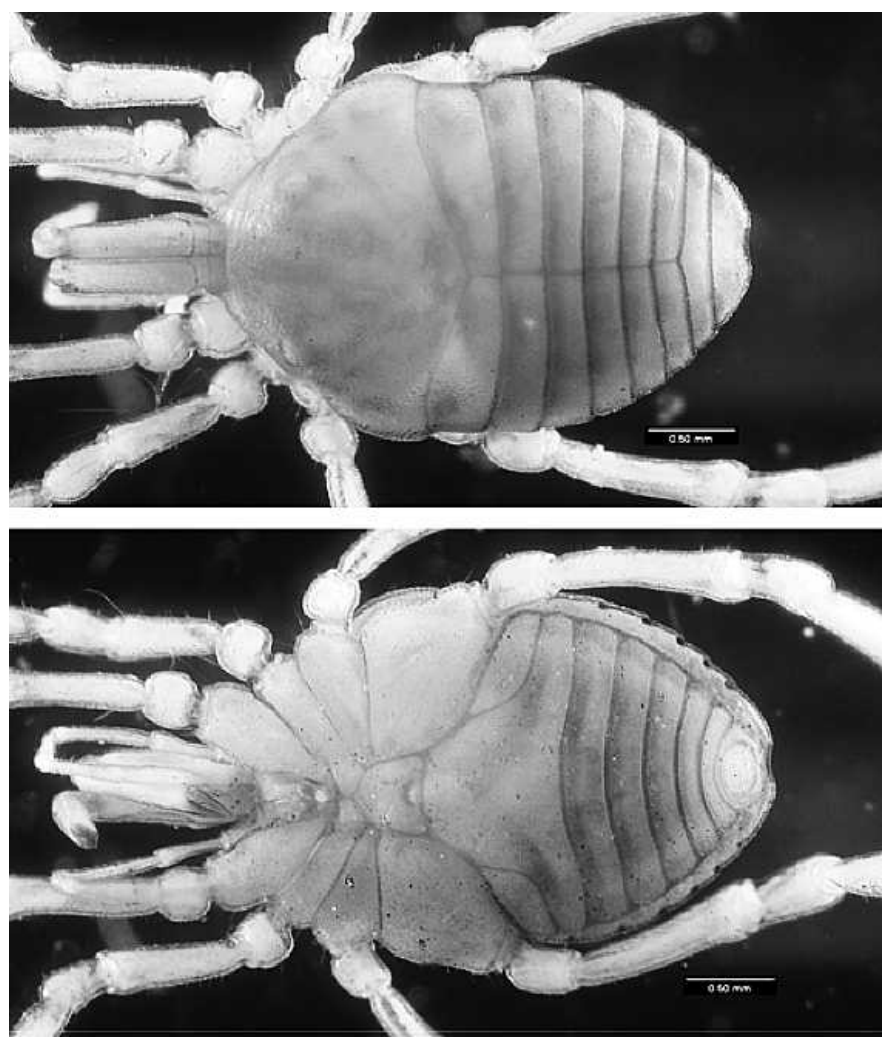

Figure 3.- Specimen of Pettalus sp. from Pundaluoya in dorsal (top), and ventral (bottom) views. Scale bar $=0.5 \mathrm{~mm}$.

cimiciformis (Fig. 1). This species was coded correctly in a cladistic analysis of cyphophthalmid relationships (Giribet \& Boyer 2002), but subsequently erroneously "corrected" in a series of later analyses and papers (Giribet 2003; Sharma \& Giribet 2006). The specimen was studied and dissected by C. Juberthie.

The second specimen ( $3 \mathrm{~mm}$; Fig. 2), a subadult male with an incipient tail and adenostyle, but still with a closed gonostome aperture, is the type specimen of $P$. brevicauda, as evidenced by the description and original illustrations by Pocock (1897).

The third specimen $(3.1 \mathrm{~mm}$; Fig. 3 ) is a juvenile from the same collection as $P$. brevicauda although due to its size (larger than the subadult type of $P$. brevicauda), it may correspond to a second species from Pundaluoya. This specimen does not have a type status and should be referred to as Pettalus sp.

Hansen \& Sørensen (1904) redescribed both species but unfortunately got the specimens mixed up, and since then there has been great confusion with respect to the identity of the species. Furthermore they illustrated a specimen of $P$. cimiciformis (their plate III, figure 2a) that does not seem to have existed, or at least that does not correspond to any specimen deposited at the NHM or illustrated in the original descriptions. Their illustrations from plate III, figure 3, labelled $P$. brevicauda correspond to the type of $P$. cimiciformis.

\section{ACKNOWLEDGMENTS}

Ligia Benavides provided the images for Figs. 1 and 2. Janet Beccalioni kindly assisted during two visits to the NHM and sent specimens on loan. Prashant Sharma provided comments on an earlier draft. Mark Harvey, Paula Cushing and an anonymous reviewer provided comments that helped to improve this note. This material is based upon work supported by the National Science Foundation under Grant No. 0236871. 


\section{LITERATURE CITED}

Boyer, S.L., R.M. Clouse, L.R. Benavides, P. Sharma, P.J. Schwendinger, I. Kuranarathna \& G. Giribet. 2007. Biogeography of the world: a case study from cyphophthalmid Opiliones, a globally distributed group of arachnids. Journal of Biogeography 34:2070-2085.

Boyer, S.L. \& G. Giribet. 2007. A new model Gondwanan taxon: systematics and biogeography of the harvestman family Pettalidae (Arachnida, Opiliones, Cyphophthalmi), with a taxonomic revision of genera from Australia and New Zealand. Cladistics 23:337-361.

Giribet, G. 2003. Karripurcellia, a new pettalid genus (Arachnida: Opiliones: Cyphophthalmi) from Western Australia, with a cladistic analysis of the family Pettalidae. Invertebrate Systematics $17: 387-406$

Giribet, G. \& S.L. Boyer. 2002. A cladistic analysis of the cyphophthalmid genera (Opiliones, Cyphophthalmi). Journal of Arachnology 30:110-128.

Hansen, H.J. \& W. Sørensen. 1904. On two orders of Arachnida: Opiliones, especially the suborder Cyphophthalmi, and Ricinulei, namely the family Cryptostemmatoidae., Cambridge University Press, Cambridge, UK. 182 pp.

Pickard-Cambridge, O. 1875. On three new and curious forms of Arachnida. Annals and Magazine of Natural History, Series 4 16:383-390.

Pinto-da-Rocha, R., G. Machado \& G. Giribet. 2007. Harvestmen: the Biology of Opiliones., Harvard University Press, Cambridge, Massachusetts. 597 pp.

Pocock, R.I. 1897. Descriptions of some new Oriental Opiliones recently received by the British Museum. Annals and Magazine of Natural History, Series 6, 19:283-292.

Sharma, P. \& G. Giribet. 2006. A new Pettalus species (Opiliones, Cyphophthalmi, Pettalidae) from Sri Lanka with a discussion on the evolution of eyes in Cyphophthalmi. Journal of Arachnology $34: 331-341$

Manuscript received 2 October 2007, revised 19 December 2007. 